
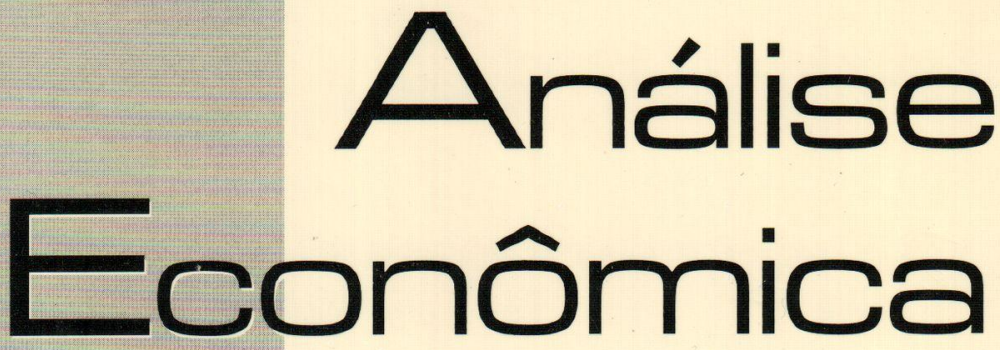

FATOS ESTHLIZADOS E CORRELAÇÁ O NO SETOR BANCÁRIO BRASILEIRO

IGOR AlexandRe C. DE MORAES

Política Monetária, Expectativas e Derivativos: uma ANALISE DO BRASIL PERIODO 1995-98

ROGERIO SOBREIRA

O FEDERAL RESERVE EM DOIS MOMENTOS DISTINTOS: ATUAÇÃO NA GRANDE DEPRESSÃO E NO FINAL DOS ANOS 1990

ROBSON RODRIGUES PEREIRA

BASHLÉIA 2 E ECONOMIAS EMERGENTES: UMA ABORDAGEM MÉDIA-VARIÁNCIA

otaViano Canuto e ANTÓ Nio josé MEIRELLES

VULNERABILIDADES EXTERNAS E INTERNAS DAS ECONOMIAS EMERGENTES E PADRÁ O DE CONTÁ GIO. A EXPERIÉnCIA DA DECADA DE 90

MiLTON PEREIRA OE ASSIS

ENDIVIDAMENTO PÚ BLICO E IMPACTO SOBRE FLUXOS DE CAPITAIS, RISCO-PAIS DIFERENCIAL DE JUROS NO BRASIL (1995-2002): MODELO VAR E TESTES DE CAUSALIDADE FLÁ VIO VILELA VIEIRA

METAS SOCIAIS DE PROCRAMAS DE MICROCRÉ DITO FINANCEIRAMENTE VIÁ VEIS

FERNANDO BATISTA PEREIRA E MARCO CROCCO

Estrutura Produtiva e Performance econó mica das ECONOMIAS ESTAdUAIS BRAsILIRAS NA DECADA DE NOVENTA ADELAR FOCHEZATTO

HISTORIA ECONO MICA Y TEORIA ECONO MICA: ENCUENTROS Y DESENCUENTROS

Gabriel PorciLe

EM BUSCA DA NOÇÃ O EVOLUCIONÁRIA (NEO-

SHUMPETERIANA) DO AUTO-INTERESSE DOS AGENTES: UMA CONTRIBUIÇAO A PARTIR DA LITERATURA SOBRE COOPERAÇÁO INTERFIRMAS

ROBSON ANTONIO GRASS

PRINCiPIOS E APULAÇó Es de REGRESSÁo Local ADALMIR MARQUETTI E LORI VIAL

globalizaçáo, Crescimento e pobreza, a Visäo do BANCO MUNDIAL SOBRE OS EFETTOS DA GLOBALIZAÇÁO NALI DE JESUS DE SOUZA

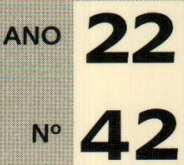




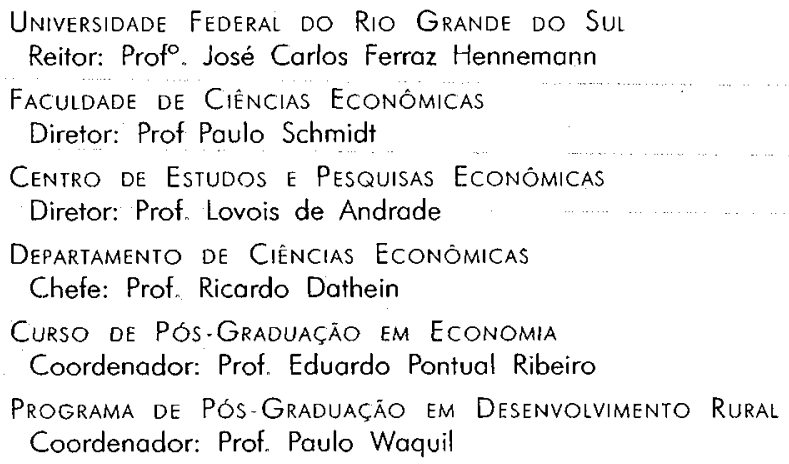

CONSELHO EDITORIAL:

André M. Cunha (UFRGS), Carlos G. A. Mieliz Netto (UFRGS), Carlos H. Hom (UFRGS), Eduardo $A_{n}$ Maldonado Filho (UFRGS), Eduardo P. Ribeiro (UFRGS), Eleutério F. S. Prado (USP), Eugênio Lagemann (UFRGS), Fernando Cardim de Carvalho (UFRJ), Fernando Ferrari Filho (UFRGS), Fernando de Holanda Barbosa (FGV/RJ), Flávio Vasconcellos Comim (UFRGS), Flávio A. Ziegelman (UFRGS), Gentil Corazza (UFRGS), Giácomo Balbinotto Netto (UFRGS), Gilberto de O. Kloeckner(UFRGS), Gustavo Franco (PUC/RJ), Hélio Henkin (UFRGS), Jairo L. Procianoy (UFRGS), Jan A. Kregel (UNCTAD), João Rogério Sanson (UFSC), Joaquim Pinto de Andrade (UnB), Jorge Paulo Araújo (UFRGS), José R. Iglesias (UFRGS), Júlio C. Oliveira (UFRGS), Luis P. Nogueról (UFGS), Luiz E. Faria (UFRGS), Marcelo S. Portugal (UFRGS), Maria Alice Lahorgue (UFRGS), Octávio A. C. Conceição (UFRGS), Orlando Martinelli (UFRGS), Paul Davidson (University of Tennessee), Paulo D. Waquil (UFRGS), Paulo Schmidt (UFRGS), Pedro C. D. Fonseca (UFRGS), Philip Arestis (University of Cambridge), Ricardo Dathein (UFRGS), Roberto C. de Moraes (UFRGS), Ronald Otto Hillbrecht (UFRGS), Sérgio M. M. Monteiro (UFRGS), Sabino da Silvo Porto Jr. (UFRGS), Stefano Florissi (UFRGS) e Werner Baer (University of Illinois at Urbana-Champaign).

COMISSÃO EDITORIAL:

Eduardo Augusto Maldonado Filho, Fernando Ferrari Filho, Gentil Corazza, Marcelo Savino Portugal, Paulo Dabdab Waquil e Roberto Camps Moraes.

EDITOR: Prof. Fernando Ferrari Filho

Egitor Adunto: Prof Gentil Corazza

Secretário: Paulo Roberto Eckent

REVISÁO DE TEXTOS: Vanete Ricacheski

Eottoraçáo Eletrónca: Nucleo de criação e editoraçáo Gráfica UFrgs: leonardo ponso Fundador: Prof. Antônio Carlos Santos Rosa

Os materiais publicados na revista Análise Econômica são da exclusiva responsabilidade dos autores. É permitida a reprodução total ou parcial dos trabalhos, desde que seja citada a fonte. Aceita-se permuta com revistas congêneres. Aceitam-se, também, livros para divulgação, elaboração de resenhas e recensōes Toda correspondência, material para publicação (vide normas na terceira capa), assinaturas e permutas devem ser dirigidos ao seguinte destinatário:

PROF. FERNANDO FERRAR! FILHO

Revista Análise Econômica - Av. João Pessoa, 52 CEP 90040-000 PORTO ALEGRE - RS, BRASIL Telefones: (051) 316-3513 - Fax: (051) 316-3990

Análise Econömíca E-mail: rae@ufrgs.br

Ano 22, $n^{\circ} 42$, morço, 2004 - Porto Alegre

Faculdade de Ciências Econômicas, UFRGS, 2004

Periodicidade semestral, março e setembro.

Tiragem: 500 exemplares

1. Teoria Econômica - Desenvolvimento Regional -

Economia Agrícola - Pesquisa Teórica e Aplicada.

Periódicos. 1. Brasil.

Faculdade de Ciências Econômicas,

Universidade Federal do Rio Grande do Sul. 


\section{Estrutura produtiva e performance econômica das economias estaduais brasileiras: 1990-2000}

Adelar Fochezatto ${ }^{1}$

Resumo: O objetivo deste trabalho é analisar a dinâmica espacial e setorial do emprego formal nas regiōes brasileiras na década de 1990. Para isso, analisam-se uma série de indicadores de estrutura e de performance econômica, bem como os relacionamentos entre eles. Os indicadores de estrutura usados na análise são: índice de Gini para avaliar o grau de dispersão espacial dos setores entre os vinte e sete estados da federação; índice de Gini para avaliar o grau de diversificação setorial de cada estado; e índice de mudança estrutural para avaliar o grau de transformação estrutural ou de mudança da composição setorial. Os indicadores de performance econômica contemplam: nível e crescimento do produto, nível e crescimento do emprego e estabilidade do produto, dado pelo coeficiente de variação do mesmo. Para analisar as relaçōes entre estes indicadores calcularam-se coeficientes de correlação.

Palavras-chave: Estrutura produtiva, mudança estrutural, performance econômica.

JEL: R10, R11.

Abstract: This paper studies the spatial and sectorial dynamics of formal employment in the Brazilian regions in the 90's. A series of structural indicators and of growth performance are analyzed. The structure indicators employed in this paper are: Gini's index to evaluate the degree of spatial dispersion of sectors between the twenty seven states of Federation; Gini's index to evaluate the degree of sectorial diversification of each state; and structural change index to evaluate the degree of structural transformation or sectorial composition change. The economic performance indicators regard level and growing of product and employment, and variability of product, given by its own variation coefficient. The relations between these indicators are analyzed by calculating correlation coefficients.

Keywords: Productive structure, structural change, economic performance.

JEL: R10, R11.

${ }^{1}$ Professor Titular da PUCRS. Doutor em Economia pela UFRGS. E-mail: adelar@pucrs.br. 


\section{Introdução}

Após um período de economia relativamente fechada e de altas taxas de inflação, o Brasil, a partir da década de 1990, entrou em uma fase de abertura comercial e de estabilização macroeconômica. Nesse período, a tarifa média de importação diminuiu significativamente e, em 1994, foi implementado o Plano Real, o qual foi acompanhado por uma política de controle cambial com forte apreciação da moeda doméstica. No período da primeira fase do Plano Real, embora tenha ocorrido uma desvalorização nominal, a moeda doméstica permaneceu sobrevalorizada e o ajuste cambial ocorreu com a mudança de regime no início de 1999, quando o país passou a adotar o sistema de câmbio flexível.

No que se refere à abertura, Pinheiro et al. (2001) afirmam que, no período de 1988 a 1995, a tarifa média sobre as importações baixou de $51 \%$ para $12 \%$, a maioria das barreiras não tarifárias foi eliminada e acabou a reserva de mercado para os setores da informática. A liberalização do comércio, além de aumentar a integração do país à economia mundial, estimulou a modernização tecnológica e o incremento da produtividade. $\mathrm{O}$ acirramento da concorrência e a facilidade de acesso ao capital estrangeiro estimularam os produtores domésticos a aumentar sua competitividade, e o resultado disso foi um aumento relativo de recursos da economia alocados para os setores transacionáveis.

Em 1994, o Brasil passou a implementar um programa de estabilização macroeconômica. Para controlar os preços, o Plano Real valeu-se especialmente das seguintes medidas de política econômica: controle da taxa de câmbio, controle da oferta de moeda e controle da taxa de juros básica. A combinação que vigorou durante a primeira fase do Plano foi a de câmbio apreciado, restrição monetária e taxa de juros relativamente elevada, provocando a queda dos preços, o aumento das importações e o aumento do déficit público. A redução da inflação, por seu lado, aumentou a demanda agregada doméstica e possibilitou, em algum grau, a substituição de importações e o aumento das exportações.

A estabilização, portanto, teve impactos favoráveis sobre alguns setores produtivos e desfavoráveis sobre outros. Em termos 
relativos, pode-se afirmar que os mais beneficiados foram os setores: a) mais dependentes de insumos importados; b) com maior elasticidade de substituição de insumos domésticos por importados; c) com menor elasticidade de substituição do produto final doméstico pelo importado; e d) com produção voltada principalmente ao mercado doméstico.

A abertura comercial, via redução de tarifas, e a estabiliza. ção macroeconômica, através do controle cambial, além de contribuírem de forma decisiva para o controle da inflação, alteraram a estrutura de preços relativos dos produtos domésticos entre si e em relação aos importados. Isto porque os setores produtivos, por apresentarem diferenças nas estruturas de custos e nos mecanismos de mercado, sofrem efeitos diferentes quando ocorre a mudança da política econômica.

As mudanças no cenário macroeconômico influenciam a estrutura setorial e espacial da produção bem como a sua produtividade. Em teoria, a abertura da economia provoca uma maior especialização produtiva, intensificando as interdependências econômicas entre as regiões. Isto ocorre porque passa a haver uma melhor utilização das vantagens comparativas por parte das economias, levando à geração de excedentes exportáveis nestes setores e à importação em outros em que elas apresentam baixa competitividade. Por isso há uma tendência crescente em articular os conceitos da Economia Internacional com os da Economia Regional.

Em suma, as políticas macroeconômicas da década de noventa, por terem alterado os preços relativos dos produtos e a alocação de recursos, certamente influenciaram a composição da estrutura produtiva, em termos de setores e regiões, e a produtividade dos fatores. Este trabalho está focado na análise destas questões para o conjunto dos estados brasileiros.

O objetivo é analisar a dinâmica espacial e setorial do emprego bem como explorar possíveis relações existentes entre a estrutura produtiva e a performance econômica das regióes (estados) brasileiras na década de 1990. Para isso, foram definidos alguns indicadores de estrutura e de desempenho econômico. Os indicadores de estrutura abrangem: grau dispersão espacial do emprego setorial, sendo que para isso foi calculado um índice de Gini ordenando os setores quanto à sua dispersão entre as regiões; grau diversidade do emprego setorial das eco- 
nomias regionais, capturada através de um índice de Gini ordenando as regiōes quanto ao seu grau de diversidade produtiva setorial; e grau de mudança na composição do emprego setorial nas regiões, capturado por um índice de mudança estrutural. Os indicadores de performance econômica contemplam: o nível e o crescimento do produto das economias regionais; o nível e o crescimento do emprego; e estabilidade do produto regional, dado pelo coeficiente de variação do mesmo. Para analisar as relações entre a estrutura produtiva e a performance econômica foram calculados coeficientes de correlação entre estes indicadores.

Este trabalho está estruturado da seguinte forma: além desta introdução, na seção dois analisam-se a dinâmica espacial do produto e do emprego no Brasil bem como os principais fatores que a influenciaram ao longo do tempo; na seção três analisamse os indicadores estruturais e de performance econômica das regiões; e, finalmente, tecem-se alguns comentários finais.

\section{Dinâmica espacial do produto e do emprego no Brasil}

A dinâmica espacial e setorial do emprego no Brasil pode ser explicada a partir de três fatores principais: políticas públicas de incentivos fiscais, de investimentos produtivos e de infra-estrutura; difusão de novas tecnologias eletrônicas e a conseqüente reestruturação dos processos produtivos; e mudanças na composição da oferta de produtos regionais decorrentes de variações ocorridas no lado da demanda.

Em relação ao primeiro fator, Diniz e Lemos (1986) afirmam que, desde meados do século XIX até aproximadamente 1970, O Brasil passou por um forte processo de concentração econômica na região de São Paulo, produzindo um modelo econômico de integração nacional com especialização regional. A partir da década de 1970, iniciou-se um período de desconcentração espacial comandado, principalmente, pelas políticas públicas de incentivos fiscais e investimentos produtivos e de infra-estrutura. Com isso, a tendência histórica de concentração econômica com especializações regionais passou gradativamente a ser substituída por outra mais dispersa espacialmente e mais diversificada setorialmente. 
A partir da década de 1980, a economia brasileira começou um intenso processo de reestruturação produtiva, decorrente da difusão de novas tecnologias de produção baseadas na microeletrônica. ${ }^{2}$ Pode-se dizer que elas, juntamente com as melhorias na infra-estrutura energética, de transporte e comunicação, aumentaram a mobilidade espacial do capital. Esta afirmativa baseia-se em dois argumentos principais: o aumento da produtividade dos fatores de produção tornou os custos de transporte relativamente menos importantes; e a maior flexibilização dos processos produtivos possibilitou a instalação de plantas produtivas eficientes menores, reduzindo os custos relativos de entrada e saída do mercado. Com isso, as empresas passaram a se deslocar mais facilmente no espaço em direção aos fatores locacionais mais convenientes, alterando o padrão produtivo da economia. Estes aspectos, no entanto, influenciaram tanto no sentido da concentração quanto no da dispersão da produção.

As mudanças na composição da oferta de produtos das regiões estão intimamente ligadas à abertura da economia ${ }^{3}$ da década de 1990 e à crescente desagregação do modelo de concentração econômica no centro com especialização produtiva regional na periferia, vigente no país até recentemente. Além da produção para o centro, as economias regionais passaram a ter, no mercado internacional, uma nova fonte de demanda para seus produtos, possibilitando a produção de outros produtos. Assim, a abertura da economia pode tanto ter aumentado quanto diminu ído a dispersão espacial e a diversificação produtiva setorial. No entanto, embora tenha aumentado o leque de opções de mercado, o mais provável é que ela tenha provocado alterações na composição da produção, especializando a produção regional naqueles setores que apresentam uma maior vantagem competitiva em relação ao mercado externo.

Os dados recentes do produto, emprego e população regional mostram que, embora ainda sejam bastante concentrados, estão gradualmente se dispersando no espaço nacional. A estrutura pro-

${ }^{2}$ Uma boa análise dos efeitos destas novas tecnologias sobre as economias em desenvolvimento, especialmente da América Latina, pode ser encontrada em Pérez (1992) e Pérez (1996).

${ }^{3}$ Moreira e Najberg (1999) analisam os efeitos da abertura comercial e da reestruturação produtiva sobre o emprego no Brasil. 
dutiva, embora ainda relativamente diversificada, está-se tornando cada vez mais especializada (ver Anexo $A$, colunas 2 e 3 ).

A Tabela 1 mostra a dinâmica espacial do produto, do emprego e da população no período em estudo. Os dados mostram que as três maiores economias regionais - São Paulo, Rio de Janeiro e Minas Gerais - foram responsáveis por aproximadamente $56 \%$ do Produto Interno Bruto do País no ano 2000. Considerando as cinco principais economias, incluindo o Rio Grande do Sul e o Paraná, a participação alcançou o patamar de $62 \%$ do produto. Durante a década de 1990, houve uma pequena diminuição desta concentração, pois, no ano de 1990, a participação das três e das cinco maiores economias era, respectivamente, de $57 \%$ e $63,5 \%$ do produto.

A concentração espacial reflete-se também, embora em níveis um pouco inferiores, no pessoal ocupado. Considerando os dois grupos de estados citados anteriormente, percebe-se que, no ano 2000 , havia $42 \%$ das pessoas ocupadas nas três maiores economias e $56 \%$ nas cinco maiores economias regionais do País. Também nesse caso, houve uma pequena redução da concentração durante a década, dado que, em 1991, esses dois grupos concentravam $44 \%$ e $57 \%$ das pessoas ocupadas na produção.

Tabela 1: Distribuição regional do produto, do pessoal ocupado e da população no Brasil (em porcentagem)

\begin{tabular}{ccccccc}
\hline Estados & \multicolumn{2}{c}{ PIB } & \multicolumn{2}{c}{ Pessoal Ocupado } & \multicolumn{2}{c}{ População } \\
\hline & 1990 & 2000 & 1991 & 2000 & 1990 & 2000 \\
\hline Três maiores(SP, RJ, MG) & 57,2 & 55,8 & 43,8 & 42,4 & 41,0 & 40,8 \\
\hline Cinco maiores(SP, RJ, MG, RS, PR) & 63,5 & 61,8 & 57,4 & 55,6 & 53,1 & 52,4 \\
\hline
\end{tabular}

Fonte: Elaboração do autor a partir dos dados das Contas Regionais do Brasil e dos Censos Demográficos, ambos do IBGE.

A concentração espacial verificada na produção e no emprego ocorre também com a população. Neste caso, no ano 2000, o grupo das três maiores economias abarcou $41 \%$ e o das cinco maiores $52 \%$ da população total do país. Também, como ocorreu com a produção e o emprego, a concentração da população teve um pequeno recuo na década, já que, em 1990, ela representava, respectivamente, $41 \%$ e $53 \%$ da população total. 
Em termos de composição do emprego, observou-se uma tendência de especialização ou redução da diversidade. ${ }^{4}$ Esta tendência representou um incremento relativo da participação do setor de serviços no produto agregado e uma redução relativa da indústria, especialmente a de transformação, e da agropecuária. A participação média da indústria em geral (incluindo a extrativa mineral, os S.I.U.P e a construção civil) no PIB, na década, ficou em torno de $39 \%$ tendo permanecido estável nesse nível. A indústria da transformação teve uma participação média de $27 \%$ do produto, tendo caído sua participação no período. A agropecuária representou $8 \%$ do produto com uma pequena queda na participação. Por fim, os serviços representaram $53 \%$ do produto e tiveram um pequeno aumento em sua participação no período analisado.

Finalmente, para fechar esta parte, é importante verificar a distribuição espacial do emprego dos setores produtivos bem como a sua evolução no período analisado. Neste sentido, os dados da Tabela 2 mostram que os setores mais dispersos nas diferentes regiões são a Administração Pública, Serviços Industriais de Utilidade Pública, Alimentação e Bebidas, Indústria Extrativa Mineral, a Construção Civil e Serviços de saúde e veterinários. No outro extremo estão os setores que apresentam maior concentração espacial do emprego. São eles: Indústria de Material de Transporte; Indústria de Calçados; Indústria Mecânica; Indústria Eletrônica e Comunicações; Indústria Metalúrgica e Indústria Química.

Observando os dados referentes à evolução deste indicador, verifica-se uma inequívoca tendência de aumento da dispersão espacial do emprego setorial no Brasil: dos 25 setores estudados, 23 aumentaram a dispersão. Apenas os setores Serviços Industriais de Utilidade Pública e Instituições Financeiras aumentaram a concentração espacial do emprego setorial. O comportamento desses dois setores certamente está ligado ao processo de privatizações e de reestruturação do sistema financeiro ocorridos ao longo da década de 1990. Os setores que mais aumentaram a dispersão espacial do emprego foram, respectivamente: Produção de Mine. rais não Metálicos; Ensino; Indústria da Alimentação e Bebidas; Indústria Têxtil; e Comércio Atacadista.

${ }^{4} \mathrm{O}$ índice de Gini da distribuição setorial do emprego aumentou ao longo da década de 1990. Ver no Anexo A os resultados referentes ao Brasil (última coluna). 
Tabela 2: Grau de dispersão regional do emprego setorial, 1990/2000

\begin{tabular}{|c|c|c|c|}
\hline Setores & $\begin{array}{l}\text { Índice } \\
\text { deGini }^{\star}\end{array}$ & Setores & $\begin{array}{c}\text { Variação do } \\
\text { índice de Gini }(\%)\end{array}$ \\
\hline Administração pública & 0,52 & Minerais não metálicos & $-4,65$ \\
\hline Serviços de utilidade pública & 0,59 & Ensino & $-4,28$ \\
\hline Alimentos e bebidas & 0,64 & Alimentos e bebidas & $-3,22$ \\
\hline Extrativa mineral & 0,64 & Têxtil e vestuário & $-3,02$ \\
\hline Construção civil & 0,65 & Comércio atacadista & $-2,97$ \\
\hline Serviços de saúde e veterinários & 0,65 & Papel, editorial e gráfica & $-2,42$ \\
\hline Ensino & 0,66 & Construção civil & $-2,37$ \\
\hline Comércio varejista & 0,66 & Comércio varejista & $-2,20$ \\
\hline $\begin{array}{c}\text { Alojamento, alimentação } \\
\text { e midia. }\end{array}$ & 0,68 & $\begin{array}{l}\text { Material elétrico } \\
\text { e comunicações }\end{array}$ & $-1,95$ \\
\hline Transportes e comunicações & 0,68 & Material de transporte & $-1,86$ \\
\hline Agropecuária & 0,69 & Indústria metalúrgica & $-1,65$ \\
\hline Comércio atacadista & 0,70 & Borracha, Fumo e Couro & $-1,56$ \\
\hline Minerais não metálicos & 0,70 & Indústria de calçados & $-1,54$ \\
\hline Madeira e mobiliário & 0,70 & Extrativa mineral & $-1,44$ \\
\hline Instituições financeiras & 0,70 & Transportes e comunicações & $-1,40$ \\
\hline $\begin{array}{l}\text { Com, de imóveis } \\
\text { e serviços técnicos }\end{array}$ & 0,73 & Químicos e plásticos & $-1,38$ \\
\hline Têxtil e vestuário & 0,76 & Madeira e mobiliário & $-1,16$ \\
\hline Papel, editorial e gráfica & 0,78 & Alojamento, alimentação e mídia & $-0,83$ \\
\hline Borracha, Fumo e Couro & 0,81 & Agropecuária & $-0,78$ \\
\hline Químicos e plásticos & 0,82 & Indústria mecânica & $-0,72$ \\
\hline Indústria metalürgica & 0,82 & Administração pública & $-0,48$ \\
\hline $\begin{array}{l}\text { Material elétrico } \\
\text { e comunicações }\end{array}$ & 0,85 & $\begin{array}{l}\text { Com. de imóveis } \\
\text { e serviços técnicos }\end{array}$ & $-0,34$ \\
\hline Indústria mecânica & 0,86 & Serviços de sauide e veterinários & $-0,04$ \\
\hline Indústria de calçados & 0,88 & Instituições financeiras & 2,40 \\
\hline Material de transporte & 0,89 & Serviços de utilidade püblica & 2,53 \\
\hline Média & 0,72 & Média & $-1,49$ \\
\hline
\end{tabular}

Fonte: elaboração do autor a partir dos dados da RAIS. (*) para ver como este indicador foi calculado, ver a subseção 3.1.2 abaixo. 


\section{Estrutura produtiva, mudanças estruturais e performance econômica}

Para analisar o padrão estrutural das regiões e suas relações com a performance econômica, foi calculado um conjunto de indicadores. O objetivo da próxima subseção é mostrar a metodologia de cálculo destes indicadores e, na seqüência, analisar os indicadores propriamente ditos.

\subsection{Considerações metodológicas}

O período analisado vai de 1990 a 2000. Sua escolha devese à disponibilidade de dados desagregados setorialmente ${ }^{5} \mathrm{e}$ ao contexto macroeconômico vigente no período. Como foi salientado na introdução, a dinâmica regional do emprego e do produto pode ser analisada a partir de três fases: até 1980, o qual se caracteriza pela forte participação do Estado em termos de investimentos produtivos e de infra-estrutura e por um ambiente macroeconômico de economia relativamente fechada e com altas taxas de crescimento econômico; década de 1980, o qual se caracteriza pela forte difusão das novas tecnologias de produção baseadas na microeletrônica e a conseqüente reestruturação produtiva; e a partir da década de 1990, que se caracteriza pela abertura da economia e a conseqüente aceleração do processo de reestruturação produtiva interna. Este trabalho, portanto, restringe-se a este último período.

Para a avaliação empírica da dinâmica do emprego regional, elaborou-se um conjunto de indicadores estruturais e de performance econômica: índice de Gini para verificar o grau de diversidade setorial do emprego nas regiões, índice de Gini para verificar o grau de dispersão regional do emprego dos setores, índice de mudança estrutural para verificar o grau de mudança da composição setorial do emprego e coeficiente de variação do produto regional para verificar o grau de instabilidade das economias regionais.

\footnotetext{
5 Os dados usados são da RAIS (Relatório Anual de Indicadores Sociais do Ministério do Trabalho). Embora a RAIS tenha dados de emprego setorial desde 1986, as séries apresentam maior estabilidade a partir da década de noventa.
} 
3.1.1 Î́dice de mudança estrutural

Este índice pode ser definido como sendo metade da soma do valor absoluto das diferenças nas proporções dos setores no emprego total regional entre dois momentos do tempo. Ele foi calculado da seguinte forma:

$$
\operatorname{IME}=1 / 2 \quad \Sigma_{\mathrm{i}}\left|\mathrm{X}_{\mathrm{i}, \mathrm{t}}-\mathrm{X}_{\mathrm{i}, \mathrm{t}-1}\right|
$$

onde $X_{i, t}$ e $X_{i, t-1}$ representam a participação do emprego do setor i no emprego total da região no período $t$ e $t-1$, respectivamente. $\mathrm{O}$ IME pode assumir valores entre zero e 1 , em que o valor zero significa que não houve nenhuma mudança estrutural enquanto que o valor 1 indica uma completa mudança da estrutura produtiva. A aplicação deste método para comparar mudanças estruturais entre regiões necessita o uso da mesma agregação de dados e do mesmo período de tempo pois os resultados são bastante sensíveis a esses dois fatores. É importante não confundir mudança estrutural com crescimento econômico. Este método captura apenas as alterações na composição do emprego ao logo do tempo, independentemente se a economia cresceu ou não. Por exemplo, se, em um determinado período, todos os setores cresceram na mesma proporção, o crescimento econômico, neste caso, seria positivo enquanto que o Índice de Mudança Estrutural seria igual a zero.

\subsection{2 Índice de Gini}

O índice de Gini mede a distribuição setorial do emprego nas regiōes: um valor próximo a zero indica que o emprego é bastante distribuído entre os 25 setores e um valor próximo a um indica que o emprego da região é mais concentrado em poucos setores. A interpretação deste indicador é, portanto, diferente daquela dos estudos de Organização Industrial, os quais medem a concentração econômica dentro de uma determinada indústria, visando identificar a relação entre o grau de concorrência e a performance econômica desta indústria (SCHERER, 1980). Ele foi calculado da seguinte forma:

Índice de Gini $=[(\mathrm{N}+1) / \mathrm{N}]-2\left(\mathrm{NL}_{1}+(\mathrm{N}-1) \mathrm{L}_{2}+\ldots+\mathrm{L}_{\mathrm{i}}\right) /\left(\mathrm{N}^{2} \mathrm{~L}\right)$ onde $\mathrm{N}$ é o número de setores; $\mathrm{L}_{1}, \mathrm{~L}_{2}, \ldots, \mathrm{L}_{\mathrm{i}}$ é o número de em- 
pregados em cada setor $\mathrm{i}$, sendo que os setores são ordenados de forma que $\mathrm{L}_{1}<\mathrm{L}_{2}<, \ldots,<\mathrm{L}_{\mathrm{i}}$; e $\mathrm{L}$ é o número médio de trabalhadores para cada setor. No cálculo do índice de Gini setorial, $\mathrm{N}$ é o número de regiões, $\mathrm{L}_{1}, \mathrm{~L}_{2}, \ldots, \mathrm{L}_{\mathrm{i}}$ é o número de empregados do setor em cada região i, sendo que as regiões são ordenadas de forma que $\mathrm{L}_{1}<\mathrm{L}_{2}<, \ldots,<\mathrm{L}_{\mathrm{i}}$; e $\mathrm{L}$ é o número médio de trabalhadores do setor para cada região.

\subsubsection{Fonte dos dados}

Os dados utilizados para calcular os indicadores acima descritos são as séries de emprego setorial do Relatório Anual de Indicadores Sociais (RAIS) do Ministério do Trabalho. ${ }^{6}$ Embora os dados de emprego setorial desta fonte sejam inferiores àqueles observados no Pessoal Ocupado setorial dos Censos Demográficos do IBGE, eles foram escolhidos para esta análise por três motivos: eles são anuais; embora subestimem o emprego setorial por levantarem apenas o emprego formal, eles apresentam uma correlação superior a 0,99 com os dados do Censos Demográficos; e eles são mais desagregados setorialmente, apresentando informações para 25 setores.

Portanto, seu uso não seria recomendável se o objetivo fosse analisar aspectos relacionados à produtividade do trabalho, pois se estaria a superestimando. No entanto, seu uso neste trabalho é adequado pois fazem-se análises referentes à composição e evolução do emprego setorial.

\subsection{Estrutura produtiva e mudanças estruturais}

$\mathrm{Na}$ seção anterior foram identificadas algumas tendências gerais em termos de evolução da composição da produção. $O$ objetivo neste momento é fazer uma análise mais desagregada, procurando identificar as principais mudanças estruturais ocorridas em nível setorial e regional. Por isso, o primeiro passo é verificar quais as regiōes que passaram por mudanças estruturais mais profundas e a direção destas mudanças em termos de com-

${ }^{6}$ As informações referentes à composição setorial e regional do produto interno bruto são das Contas Regionais do IBGE (2002), disponível em CD-Rom. 
posição da produção. Para tanto, foram calculados índices de mudança estrutural, de diversidade e de diversificação produtiva. Estes indicadores encontram-se no Anexo A.

Os indicadores de diversidade setorial, mudança estrutural e performance econômica, em tese, se interligam da seguinte forma: regiões com menor diversificação setorial tendem a apresentar maiores mudanças estruturais e maiores oscilações no produto e emprego e regiões mais diversificadas tendem a apresentar comportamento mais estável, tanto em termos estruturais quanto no produto e emprego. O primeiro caso é mais freqüente em economias menos desenvolvidas, enquanto que o segundo caso está associado a economias relativamente mais maduras e desenvolvidas. O objetivo a seguir é verificar empiricamente estas hipóteses para o caso brasileiro no período de 1990 a 2000.

Observando isoladamente o índice de mudança estrutural da Figura 1, pode-se verificar que a maioria dos estados teve mudanças estruturais acima da média (grupos 1 e 2). As maiores mudanças estruturais ocorreram nas regiões Norte, Centro-Oeste e Sudeste. Na região Nordeste, pouco menos da metade dos estados tiveram mudanças superiores à média. Um fato que deve ser destacado é que todos os estados da região Sul apresentaram mudanças abaixo da média, o que demostra uma maior estabilidade em suas estruturas produtivas. As mudanças estruturais mais profundas $^{7}$ ocorreram em estados localizados nas regiões Norte e CentroOeste. Isto reflete o fato de estas regiões, desde a década de 1970, terem-se tornado a nova fronteira de produção agropecuária e extrativa vegetal, mostrando, desde então, um forte dinamismo econômico com um processo acelerado de urbanização.

Analisando o Índice de Gini, pode-se perceber que as economias regionais mais desenvolvidas ${ }^{8}$ são mais diversificadas que as demais (grupos 1 e 4). Com exceção dos estados do Rio de Janeiro e Espírito Santo, todos os demais estados das regióes Sul e Sudeste apresentam economias mais diversificadas que a média dos estados. Por outro lado, todas as regiōes menos desenvolvidas apresentam estruturas produtivas mais especializadas que a média.

${ }^{7}$ Os valores dos índices estão no Anexo A.

${ }^{8}$ Para simplificar a análise, utiliza-se com freqüência a classificação dos estados em regióes mais e menos desenvolvidas. As regióes Sudeste e Sul são consideradas as mais desenvolvidas e as demais, menos desenvolvidas. 


\begin{tabular}{|c|c|c|}
\hline \multirow[t]{2}{*}{ IME } & Grupo 1: Alto IME e Baixo Índice de Gini & Grupo 2: Alto IME e Alto Índice de Gini \\
\hline & São Paulo & $\begin{array}{l}\text { Rondônia, Amazonas, Roraima, Amapá, } \\
\text { Tocantins, Rio Grande do Norte, Pernambuco, } \\
\text { Alagoas, Sergipe, Espirito Santo, Rio de Janeiro, } \\
\text { Mato Grosso, Mato Grosso do Sul, Goiás }\end{array}$ \\
\hline \multirow[t]{2}{*}{0,12} & Grupo 4: Baixo IME e Baixo Índice de Gini & Grupo 3: Baixo IME e Alto índice de Gini \\
\hline & $\begin{array}{c}\text { Minas Gerais, Paraná, Santa Catarina, } \\
\text { Rio Grande do Sul }\end{array}$ & $\begin{array}{l}\text { Acre, Pará, Maranhão, Piaui, Ceará, } \\
\text { Paraiba, Bahia, Distrito Federal }\end{array}$ \\
\hline
\end{tabular}

\section{Figura 1: Mudanças estruturais e padrão de distribuị̧ão setorial do emprego regional, 1990/2000}

Fonte: Elaboração do autor a partir do Anexo A

Obs: O IME e o Índice de Gini do conjunto dos estados foram, respectivamente, iguais a 0,12 e 0,54. O coeficiente de correlação entre o IME e o Índice de Gini foi igual a 0,38 .

Analisando de forma conjunta os indicadores de mudanças estruturais e de diversificação/especialização da estrutura produtiva, pode-se dizer que, em geral, há uma forte associação entre estrutura produtiva especializada e altas mudanças estruturais. A maioria dos estados da federação apresentou estruturas produtivas especializadas e fortes mudanças estruturais. Por outro lado, os estados da região sul mais Minas Gerais apresentaram um perfil produtivo diversificado e estabilidade estrutural no período analisado. É importante registrar, também, que a maior economia do País, que influenciou o padrão espacial da produção brasileira ao longo dos últimos anos, embora continue tendo uma estrutura produtiva mais diversificada que a média, apresentou um forte movimento de mudança estrutural.

O objetivo a seguir é investigar se as mudanças verificadas nas estruturas produtivas ocorreram no sentido da especialização ou diversificação. A Figura 2 classifica os estados em mudanças estruturais e variações nos índices de Gini. Considerando a evolução da estrutura produtiva na década, embora no conjunto dos estados tenha havido um aumento da especialização (ver o Anexo A), pode-se identificar uma tendência de diversificação econômica na maioria dos estados (grupos 1 e 4). O grupo mais numeroso de estados é o que teve alta mudança na estrutura produtiva na direção de um aumento da diversificação (grupo1). No entanto, 
deve-se destacar que as duas maiores economias do país, São Paulo e Rio de Janeiro, apresentaram um movimento no sentido da especialização produtiva. Assim, pode-se dizer que a tendência verificada no período é de especialização nas economias centrais e de diversificação nas periféricas.

Com as informações analisadas até o momento, pode-se tirar uma primeira lição. Na década de 1990, houve seguimento na tendência de maior dispersão espacial da atividade econômica, como já fora constatado por Diniz e Lemos (1986) e por Cano (1975).${ }^{9}$ O fato novo a ser destacado é que esta tendência está sendo acompanhada por uma nova dinâmica: gradual especialização nas economias dos estados do centro e diversificação nas economias periféricas.

\begin{tabular}{|c|c|c|}
\hline IME & Grupo 1: Alto IME e Baixa D Índice de Gini & Grupo 2: Alto IME e Alta D Índice de Gini \\
\hline \multirow{3}{*}{0,12} & $\begin{array}{l}\text { Rondônia, Amazonas, Amapá } \\
\text { Rio Grande do Norte, Alagoas, Sergipe, } \\
\text { Espírito Santo, Mato Grosso, Goiás }\end{array}$ & $\begin{array}{l}\text { Roraima, Tocantins, Pernambuco, } \\
\text { Rio de Janeiro, São Paulo } \\
\text { Mato Grosso do Sul }\end{array}$ \\
\hline & Grupo 4: Baixo IME e Baixa D Índice de Gini & Grupo 3: Baixo IME e Alta D Índice de Gini \\
\hline & $\begin{array}{l}\text { Acre, Piauí, Ceará, Paraiba, Paraná, } \\
\text { Rio Grande do Sul, Distrito Federal }\end{array}$ & $\begin{array}{l}\text { Pará, Maranhão, Bahia, } \\
\text { Minas Gerais, Santa Catarina }\end{array}$ \\
\hline
\end{tabular}

\section{Figura 2: Mudanças estruturais e mudanças no padrão de distribuição setorial do emprego regional, 1990/2000}

Fonte: Elaboração do autor a partir do Anexo A. Obs.: A variação do Índice de Gini no conjunto dos estados foi igual a $5,66 \%$, denotando um aumento da especialização produtiva. O coeficiente de correlação entre o IME e a Variação do Índice de Gini foi igual a 0,29 .

\subsection{Perfil estrutural e performance econômica}

Após a análise das mudanças estruturais e do padrão de alocação setorial do emprego regional, é importante investigar as relações que elas apresentam com a performance econômica das

\footnotetext{
${ }^{9}$ De acordo com Cano (1975), o padrão de concentração econômica em São Paulo apresentou uma diversificação no Centro e uma especialização e fragmentação na periferia. Dentro da divisão inter-regional do trabalho, cada região se inseriu com determinadas atividades especializadas no conjunto da economia nacional. $\mathrm{Na}$ opinião de Diniz e Lemos (1986), esta divisão inter-regional do trabalho produziu um modelo de integração nacional e de especialização regional.
} 
regiōes em termos de crescimento do produto e do emprego e estabilidade econômica. Para detectar estas relações, foram calculadas as correlações entre estas variáveis. Os resultados destes cálculos estão na tabela 3 .

A análise das relações entre estrutura e mudança estrutural, diversidade e diversificação de atividades produtivas e performance econômica em termos de crescimento e estabilidade são tradicionais nos estudos de economia regional. A principal hipótese testada, e confirmada, na maioria dos trabalhos preocupados com estes relacionamentos, é a que regiões com maior diversidade produtiva apresentam melhor desempenho econômico (HOOVER e GIARRATANI, 1985, p. 371).

Para testar esta hipótese, uma série de indicadores é calculada visando possibilitar uma análise comparativa entre diferentes regiões. Os principais indicadores usados referem-se a medidas de diversidade e de diversificação econômica e medidas de níveis e estabilidade do emprego e/ou do produto. Uma das principais críticas feitas a estes estudos é que muitos deles analisam apenas variáveis estáticas e/ou utilizam inadequadamente alguns indicadores (MALIZIA, 1990, p. 34). Segundo esse autor, um dos principais exemplos é o uso do indicador de diversidade como sendo o mesmo de diversificação. A diferença básica entre eles é que o primeiro é estático e indica o padrão estrutural em que a região se encontra (mais ou menos diversificada), e o segundo indica a mudança deste padrão ao longo de um determinado período de tempo (aumento ou diminuição da diversidade).

Neste trabalho, foram calculados indicadores estáticos e dinâmicos. Foram calculadas correlações entre as seguintes variáveis: índice de Gini, crescimento do índice de Gini, índice de mudança estrutural, nível e crescimento do emprego regional, nível e crescimento do produto interno bruto regional e coeficiente de variação do produto regional. As variáveis em nível foram calculadas em termos médios sobre o período, e as variáveis que representam crescimento, mudança estrutural e coeficiente de variação foram calculadas para o período de 1990 a 2000.

Desta forma, o índice de Gini da Tabela 3 de correlações é um indicador do grau de diversidade setorial do emprego regional. O crescimento do índice de Gini é um indicador de diversificação e pode ser interpretado como um sinalizador do processo de transformação estrutural da região. A diferença em relação ao 
índice de mudança estrutural é que ele evidencia o sentido da mudança (diversificação/especialização) enquanto que o outro mostra apenas a magnitude da mudança.

$\mathrm{Na}$ literatura sobre desenvolvimento econômico, o processo de transformação estrutural das economias é um aspecto central para entender a dinâmica evolutiva das mesmas. A partir de uma economia baseada em atividades primárias, as transformações traduzem-se, inicialmente, em um crescimento relativamente maior do setor secundário e, posteriormente, do setor terciário. Estas mudanças são induzidas pelas mudanças na demanda doméstica de produtos, pelas novas tecnologias de produção e pelos novos fluxos comerciais com o exterior (SYRQUIN, 1988). Assim, o processo de transformação estrutural de uma economia em desenvolvimento resulta em uma constante alteração da importância relativa dos setores e, em cada momento, há atividades em expansão e em declínio. À medida que a economia se desenvolve, a magnitude das transformações passa a ser cada vez menor e tende a alcançar uma estrutura produtiva mais estável.

A partir dessas correlações, e considerando-se apenas as relações mais fortes, pode-se destacar os seguintes aspectos: um maior nível de produto está associado a um maior nível de emprego $(0,67)$ e a uma maior instabilidade do produto $(0,58)$; uma maior especialização setorial está associada a um menor nível de emprego $(-0,67)$ e um menor nível de produto agregado $(-0,66)$; e um crescimento do índice de especialização está associado a um menor crescimento do emprego $(-0,57)$.

Pode-se destacar outras correlações importantes, embora de menor intensidade: uma maior mudança estrutural das regiões está associada a uma maior especialização da estrutura produtiva $(0,38)$; um maior nível de especialização regional está associado a uma maior instabilidade do produto $(0,40)$ um maior crescimento do produto está associado a um maior crescimento do emprego $(0,40)$; e as regiões que apresentaram um maior nível de produto e de emprego tiveram um comportamento mais estável em suas economias $(-0,24)$ e $(-0,26)$.

Uma outra lição pode ser tirada dos resultados destas correlaçōes. As regiões relativamente mais diversificadas apresentam maiores níveis de produto e de emprego e maior estabilidade eco- 
Tabela 3: Matriz de correlações entre indicadores estruturais e de performance econômica regional, 1990/2000

\begin{tabular}{|c|c|c|c|c|c|c|c|}
\hline $\begin{array}{l}\text { Indice } \\
\text { de Gini }\end{array}$ & $\begin{array}{l}\text { Crescimento do } \\
\text { indice de Gini }\end{array}$ & $\begin{array}{l}\text { Índice de } \\
\text { mudançaa } \\
\text { estrutural }\end{array}$ & Emprego & $\begin{array}{l}\text { Crescimento } \\
\text { do emprego }\end{array}$ & PIB & $\begin{array}{l}\text { Crescimento } \\
\text { do PIB }\end{array}$ & $\begin{array}{c}\text { Coeficiente } \\
\text { de variação } \\
\text { do PIB }\end{array}$ \\
\hline \multicolumn{8}{|l|}{1,00} \\
\hline$-0,33$ & 1,00 & & & & & & \\
\hline 0,38 & $-0,43$ & 1,00 & & & & & \\
\hline$-0,67$ & 0,18 & $-0,18$ & 1,00 & & & & \\
\hline 0,32 & $-0,57$ & 0,67 & $-0,21$ & 1,00 & & & \\
\hline$-0,66$ & 0,18 & $-0,16$ & 0,99 & $-0,20$ & 1,00 & & \\
\hline 0,24 & $-0,09$ & 0,10 & $-0,21$ & 0,40 & $-0,21$ & 1,00 & \\
\hline 0,40 & $-0,04$ & 0,58 & $-0,26$ & 0,12 & $-0,24$ & $-0,18$ & 1,00 \\
\hline
\end{tabular}

Fonte: Elaboração do autor.

Obs.: Os dados brutos de emprego são da RAIS e os dados do PIB dos estados são do IBGE.

nômica. As mudanças estruturais provocam instabilidade nas economias mas são benéficas para o crescimento do emprego, desde que não impliquem em aumento da especialização produtiva. As regiões com menores níveis de produto interno e emprego tendem a apresentar mudanças estruturais mais intensas.

\section{$3.4 \bigcirc$ papel dos setores agroindustriais}

Uma das hipóteses levantadas em estudos sobre estrutura produtiva e performance econômica regional é a de que os setores agroindustriais desempenham um importante papel por causa de suas fortes ligações intersetoriais. ${ }^{10} \mathrm{O}$ objetivo desta subseção é investigar o papel que estes setores ${ }^{11}$ desempenharam na dinâmica regional do emprego durante o período em questão. Mais especificamente, o objetivo a seguir é avaliar até que ponto os

10 Ver, por exemplo, Accurso (2002)

${ }^{11}$ Neste trabalho, consideram-se como setores agroindustriais os seguintes: Indústria da Madeira e do Mobiliário; Indústria da Borracha, Fumo e Couros; Indústria Têxtil; Indústria de Calçados; Indústria da Alimentaçāo e Bebidas; e Agricultura. 
setores agroindustriais estão ligados aos indicadores de diversificação produtiva e de mudança estrutural.

A Tabela 2 mostra que alguns setores apresentam produção bastante dispersa e outros bastante concentrada. Os setores mais distribuídos regionalmente são a Indústria da Alimentação e Bebidas; a Agricultura; e a Indústria da Madeira e do Mobiliário. A Indústria Têxtil e a Indústria da Borracha, Fumo e Couros estão numa posição intermediária, embora estejam mais concentrados que a média dos setores. A Indústria de Calçados, por sua vez, aparece como sendo o segundo setor mais concentrado entre todos os setores.

Em termos de evolução do grau de dispersão destes setores, verifica-se que a maioria deles teve um aumento da dispersão espacial do emprego acima da média dos setores. Neste grupo estão a Indústria da Alimentação e Bebidas; a Indústria Têxtil; a Indústria da Borracha, Fumo e Couros; e a Indústria de Calçados. A Indústria da Madeira e do Mobiliário ficou em uma posição intermediária, mas abaixo da média dos setores. Finalmente, de forma surpreendente, a Agricultura ficou entre os setores que menos se desconcentraram. Merece destaque o fenômeno verificado com a Indústria de Calçados pois, se, por um lado, ele é um dos setores mais concentrados, por outro, ele apresentou um forte movimento de desconcentração durante o período analisado. Isto deve estar refletindo o processo de expansão e de migração interregional de indústrias do setor, especialmente da região Sul para a região Nordeste. ${ }^{12}$

Após analisar as características dos setores agroindustriais em termos de grau de distribuição regional e em relação aos seus movimentos de dispersão ou concentração, é importante verificar o grau de relacionamento que estes setores têm com os indicadores estruturais e de performance econômica das regióes. Para isso, foram calculadas as correlações entre as variáveis pertinentes, e os resultados estão registrados na Tabela 4.

${ }^{12}$ Em relação a esta questão, um relato da Federação das Indústrias do Estado do Rio Grande do Sul (FIERGS) afirma o seguinte: a) as transferências para outros estados (especialmente para o Nordeste) ocorreram principalmente no setor calçadista; b) com exceção da Grendene, que transferiu totalmente sua planta de Farroupilha/RS para Sobral/ $\mathrm{CE}$, as empresas apenas expandiram suas atividades abrindo filiais em outros estados; c) os principais motivos alegados para justificar a transferência/expansão são os incentivos fiscais, a proximidade do mercado centro-americano, custo barato da mão-de-obra e a existência de matérias-primas (Pólo Petroquímico de Camaçari). 
Os primeiros aspectos importantes a considerar são: todos os setores agroindustriais apresentaram correlação negativa com $o$ índice de Gini e com o índice de mudança estrutural. Em linhas gerais, isso significa dizer que regióes que apresentam uma participação relativamente maior de emprego agroindustrial no total são regiões mais diversificadas e com menores mudanças estruturais. Se forem consideradas apenas as correlações mais fortes, acima de 0,50 , o que se pode afirmar é que há uma clara associação entre a presença de setores agroindustriais e diversidade econômica regional.

Observando os resultados das correlaçōes com os indicadores de performance econômica, pode-se perceber que o único setor que possui associação relativamente forte com os indicadores econômicos é o da Indústria da Borracha, Fumo e Cou-

Tabela 4: Matriz de correlações entre participação do emprego agroindustrial e indicadores estruturais e de performance econômica regional, 1990/2000

\begin{tabular}{|c|c|c|c|c|c|c|c|}
\hline Indicadores & $\begin{array}{l}\text { Madeira e } \\
\text { mobiliário }\end{array}$ & $\begin{array}{l}\text { Borracha, } \\
\text { fumo, couro }\end{array}$ & $\begin{array}{l}\text { Indústria } \\
\text { têxtil }\end{array}$ & $\begin{array}{l}\text { Indústria } \\
\text { de } \\
\text { calçados }\end{array}$ & $\begin{array}{l}\text { Alimentos } \\
\text { ebebidas }\end{array}$ & Agropecuária & $\begin{array}{c}\text { Total } \\
\text { Agro-indüstria }\end{array}$ \\
\hline \multicolumn{8}{|l|}{$\begin{array}{c}\text { Indicadores } \\
\text { estruturais }\end{array}$} \\
\hline İndice de Gini & $-0,20$ & $-0,70$ & $-0,53$ & $-0,36$ & $-0,10$ & $-0,18$ & $-0,47$ \\
\hline $\begin{array}{l}\text { Variação do } \\
\text { İndice de Gini }\end{array}$ & 0,03 & 0,36 & 0,18 & 0,36 & $-0,09$ & $-0,23$ & 0,01 ' \\
\hline $\begin{array}{l}\text { Índice de } \\
\text { mudança } \\
\text { estrutural }\end{array}$ & $-0,19$ & $-0,22$ & $-0,35$ & $-0,24$ & $-0,15$ & $-0,03$ & $-0,31$ \\
\hline \multicolumn{8}{|l|}{$\begin{array}{l}\text { Indicadores de } \\
\text { performance } \\
\text { econômica }\end{array}$} \\
\hline Emprego & $-0,08$ & 0,51 & 0,17 & 0,13 & $-0,04$ & 0,01 & 0,07 \\
\hline $\begin{array}{l}\text { Crescimento do } \\
\text { emprego }\end{array}$ & $-0,07$ & $-0,21$ & $-0,25$ & $-0,15$ & $-0,20$ & 0,07 & $-0,20$ \\
\hline PIB & $-0,06$ & 0,52 & 0,15 & 0,12 & $-0,06$ & 0,00 & 0,06 \\
\hline $\begin{array}{l}\text { Crescimento } \\
\text { do PIB }\end{array}$ & 0,16 & $-0,23$ & $-0,08$ & $-0,12$ & $-0,17$ & 0,26 & 0,02 \\
\hline $\begin{array}{l}\text { Coeficiente de } \\
\text { Variação do PIB }\end{array}$ & 0,18 & $-0,29$ & $-0,32$ & $-0,15$ & $-0,19$ & $-0,28$ & $-0,31$ \\
\hline
\end{tabular}

Fonte: Elaboração do autor. 
ro. Pelos dados, regiões que apresentam maior participação deste setor na economia possuem maior nível de emprego $(0,51)$ e maior nível de produto $(0,52)$. Como foi visto anteriormente, este é um setor relativamente concentrado espacialmente, mas que apresentou um significativo aumento de sua dispersão no período analisado.

Outro aspecto interessante a ser destacado é que, embora com níveis de correlação relativamente baixos, praticamente todos os setores agroindustriais, exceto a Indústria da Madeira e do Mobiliário e a Agricultura, apresentaram associação negativa com os indicadores dinâmicos: variação do produto e do emprego e coeficiente de variação do produto. Isto significa dizer que estes setores, em geral, não contribuíram de forma significativa para o crescimento do produto e do emprego, e que as regióes com forte participação destes setores permaneceram em uma situação estável no período.

Por outro lado, a maioria destes setores, exceto a Indústria da Madeira e do Mobiliário e da Indústria de Alimentos e Bebidas, apresentou associação positiva com os indicadores estáticos: níveis de produto e de emprego. Estes resultados são consistentes com os encontrados anteriormente em relação ao índice de Gini e de mudança estrutural.

A partir destes resultados, uma terceira lição pode ser tirada. Pode-se dizer que as regiões que possuem uma maior participação relativa de emprego agroindustrial tendem a ser regiões mais diversificadas e mais estáveis estruturalmente. Em termos de performance econômica, pode-se dizer elas tendem a ter níveis relativamente maiores de produto e de emprego e relativamente menores oscilações do produto ao longo do tempo. Em contrapartida, elas tendem a ter um dinamismo relativamente menor em termos de crescimento do produto e do emprego.

\section{Comentários finais}

Dado o caráter exploratório deste trabalho, não se pode tirar conclusōes definitivas sobre os resultados encontrados. Além disso, os indicadores analisados são sensíveis a mudanças no ambiente macroeconômico e, por isso, apenas podem ser interpreta- 
dos à luz das políticas vigentes no período analisado. Isso significa dizer que os resultados encontrados foram condicionados, especialmente, pela abertura comercial verificada a partir do início da década e pela estabilização macroeconômica, ancorada em um regime de câmbio controlado e sobrevalorizado, a partir da metade da década de 1990.

No entanto, o conjunto de indicadores usados e os cruzamentos feitos entre eles possibilitam, com razoável grau de segurança, que dele se tire algumas lições importantes. Primeiro, os dados mostram que houve uma pequena desconcentração espacial do produto, do emprego e da população no período analisado. As regiões mais desenvolvidas, do Sudeste e do Sul, tiveram uma pequena redução em sua participação no total destas variáveis. Com isso, pode-se afirmar que a década de 1990 deu se. qüência à tendência de maior dispersão espacial da atividade econômica, constatada anteriormente por Diniz e Lemos (1986), e Cano (1975).

Segundo, junto com o movimento de maior dispersão espacial da atividade econômica, um fato novo foi constatado: esta tendência está sendo acompanhada por uma nova dinâmica que é de gradual especialização das economias mais desenvolvidas, especialmente São Paulo e Rio de Janeiro, e diversificação nas economias ditas periféricas, especialmente aquelas situadas nas regiões Norte e Centro-Oeste.

Terceiro, as relações entre estrutura e performance confir mam as hipóteses de que economias mais especializadas tendem a ser mais instáveis e vice-versa. Além disso, os resultados confirmam, também, que economias mais desenvolvidas tendem a ser mais diversificadas e mais estáveis estrutural e economicamente. No caso brasileiro, o crescimento do emprego foi relativamente maior nas regiões que apresentaram maiores mudanças estruturais e estas foram mais intensas em regiões com menores níveis de produto interno e emprego.

Finalmente, pode-se dizer que as regiões que possuem uma maior participação relativa de emprego agroindustrial tendem a ser mais diversificadas e mais estáveis. Em termos de performance econômica, estas regiões apresentaram níveis relativamente maiores do produto agregado e de emprego e baixo dinamismo em termos de crescimento. 
Embora não seja possível fazer inferências sobre o sentido das causalidades das correlações encontradas entre os indicadores estruturais e de performance econômica das regiões, ficou evidente a relação entre diversidade produtiva e estabilidade estrutural e econômica. Ficou claro, também, a importância dos setores agroindustriais em conferir estas características às regiões. Com isso, uma estratégia inteligente seria buscar o desenvolvimento econômico sem deixar que estes setores percam demasiadamente sua participação na economia.

\section{Referências bibliográficas}

ACCURSO, C.F. Estratégias de desenvolvimento para o Rio Grande do Sul. Ensaios FEE, Porto Alegre, v.23, número especial, p. 331-694, 2002.

ALWANG, J. e Siegel P.B. Portfolio Models and Planning for Export Diversification: Malawi, Tanzania and Zimbabwe. Journal of Development Studies. 30, p. 405-422, 1994.

ANDRIKOPOULOS, A; Brox, J. e Carvalho, E. 1990. Shift-Share Analysis and the Potential for Predicting Regional Growth Patterns: Some Evidence for the Region of Quebec, Canada. Growth and Change. 21, p. I-10, 1990.

ATTARAN, M. Industrial Diversity and Economic Performance. The Annals of Regional Science. 20, p. 44-54, 1986.

ATTARAN, M. e ZWICK, M. The Effect of Industrial Diversification on Employment and Income: A Case Study. The Quarterly Review of Economics and Business. 19, p. 40-54, 1987.

BREWER, H.L. Measure of Diversification: Predictors of Regional Economic Instability. Journal of Regional Science. 25, p. 463-470, 1985.

CANO, W. Raizes da concentração industrial em São Paulo. Campinas: UNICAMP, 1975. (tese de doutorado).

CRIHFIELD, J.B. e H.S. Campbell. H.S. Evaluating Alternative Regional Planning Models. Growth and Change. 22, p. 1.16, 1991.

DEMING, W.G. A decade of economic change and population shifts in U.S. regions. Monthly Labor Review, p. 3-14, nov. 1996.

DINIZ, C.C. A dinâmica regional recente da economia brasileira e suas perspectivas. Rio de Janeiro: IPEA, TD n. 375, 1995.

DINIZ, C.C.; Lemos, M.B. Mudança do padrão regional brasileiro: determinantes e implicações. Análise Conjuntural. Curitiba: Ipardes, v.8, n.2, p. 32-42, fev. 1986.

HADDAD, P.R. (org). Economia Regional. Teorias e Métodos de Análise. Fortaleza: Banco do Nordeste do Brasil, 1989.

HERZOG, H.W. e Olsen, R.J. Shift-Share Analysis Revisited: The Allocation Effect and the Stability of Regional Structure. Joumal of Regional Science, v. 17, n.3, p. 441-454, 1977.

HARRIS, D.J. Uneven Development. In: Eatwell, J.; Milgate, M. e Newman, P. (Ed.) Economic Development: The New Palgrave, Norton and Company: New York, NY, 1989. 
HIRSCHMAN, A.O. Linkages. In: Eatwell, J.; Milgate, M. e Newman, P. (Ed.) Economic Development: The New Palgrave, Norton and Company: New York, NY, 1989.

HOOVER, E.M. e GIARRATANI, F. An Introduction to Regional Economics. $3^{\circ}$ Edição. Alfred A. Knopf: New York, NY, 1985.

Instituto Brasileiro de Geografia e Estatística - IBGE. Contas Regionais do Brasil. CDRom, 2002.

ISSERMAN, A.M. Lost in Space? On the History, Status, and Future of Regional Science. Review of Regional Studies. 23, p. 1-50, 1993.

JACKSON, R.W. An Evaluation of Alternative Measures of Regional Industrial Diversification. Regional Studies. 18, p. 103-112, 1984.

KIM, S. Expansion of markets and the geographic distribution of economic activities: the trends in U.S. regional manufacturing structure, 1860-1987. Quartely Journal of Economics. V.CX, n.4, 1995.

KORT, J.R. Regional Economic Instability and Industrial Diversification in the U.S. Land Economics. 57, p. 596-608, 1981.

KRUGMAN, P.; Venables, A.J. Globalization and the inequality of nations. Quartely Journal of Economics. V.CX, n. 4, 1995.

LYNCH, L.K. Economic Structure and Economic Performance. Regional Science Perspectives. 9, p. 84-95, 1979.

MALIZIA, E.E. Economic Growth and Economic Development: Concepts and Measures. Review of Regional Studies. 20, p .30-36, 1990.

MALIZIA, E.E. e Ke, S. The Influence of Economic Diversity on Unemployment and Stability. Journal of Regional Science. 33, p. 221-235, 1993.

MARSHALL, J.U. City Size, Economic Diversity, and Functional Type: The Canadian Case. Economic Geography. 51, p. 35-49, 1975.

Ministério do Trabalho. Relatório Anual de Indicadores Sociais - RAIS. Brasília, 1986/ 2000.

MOREIRA, M.M. e Najberg, S. O impacto da abertura comercial sobre o emprego: 19901997. In: Giambiagi, F. e Moreira, M.M. (Org.) A economia brasileira nos anos 90. Rio de Janeiro: BNDES, 1999.

MUENDLER, M. Trade, technology, and productivity: a study of Brazilian manufacturers, 1986-1998. Berkeley: University of California, 2001.

PÉREZ, C. Microeletronics, long wages and world structural change: new perspectives for developing countries. World Development, vol. 13, $\mathrm{n}^{\mathrm{o}}$. 3, p. 441-463. s.d.

PÉREZ, C. Las nuevas tecnologías : una visión de conjunto. In: Ominami, C. (ed.). La tercera revolución industrial. Grupo Editor Latinoamericano, Buenos Aires, 1986, p. 43-90.

PÉREZ, C. Cambio técnico, restruturación competitiva y reforma institucional en los paises en desarrollo. El Trimestre Económico, nº. 233, jan.-mar./1992, p. 23-64.

PÉREZ, C. La modernización industrial en América Latina y la herencia de la sustitución de importaciones. Comercio Exterior, vol.46, nº. 5, México, maio/1996, p. 347-363.

PINHEIRO, A. C.; GIAMBIAGI, F. e MOREIRA, M. M. O Brasil na década de 90: uma transição bem-sucedida?Rio de Janeiro: BNDES, Departamento Econômico - DEPEC, 2001. 36p. (Textos para discussão, n. 91). 
PRADO, Eleutério F. S. Estrutura Tecnológica e Desenvolvimento Regional. São Paulo, IPEA/USP, 1981. 257p. (Coleção Ensaios Econômicos n. 10)

RICHARDSON, H.W. Insumo-Produto e Economia Regional. Rio de Janeiro: Zahar Editores, 1978.

RICHARDSON, H.W. The state of regional economics, a survey article. International Regional Science Review, n.3, p.1-48, 1978.

SCHERER, F.M. Industrial Market Structure and Economic Performance. $2^{\circ}$ Edição. Houghton Mifflin Company: Boston, 1980.

SCHOENING, N.C. e SWEENEY, L.E. Applying an Industrial Diversification Decision Model to Small Regions. Review of Regional Studies. 19, p. 14-17, 1989.

SCHUH, E. e BARGHOUTI, S. Agricultural Diversification in Asia. Finance and Development. 25, p. 41-44, 1988.

SCITOVSKY, T. Balanced Growth. In: Eatwell, J.; Milgate, M. e Newman, P. (Ed.) Economic Development: The New Palgrave, Norton and Company: New York, NY, 1989.

SIEGEL, P.B; JOHNSON, T.G e ALWANG, J. Regional economic diversity and seeking a framework for analysis. Growth and Change 26(2) 1995, p. 261-284.

SMITH, E.D. Economic Stability and Economic Growth in Rural Communities: Dimensions Relevant to Local Employment Creation Strategy. Growth and Change. 21, p. 3-18, 1990. SOUZA, N.J. Desenvolvimento Regional. Porto Alegre: PPGR/UFRGS, 1999 (versão preliminar).

SOUZ.A, N.J. Fatores de crescimento, mudança estrutural e indicadores de desenvolvimento da Região Sul, 1980/1995. Porto Alegre: UFRGS, Curso de Pós-Graduação em Economia, 1998.

SOUZA, N.J. Evolução da Estrutura Econômica do Brasil e dos Estados da Região Sul entre 1985 e 1995. In: Montoya, M.A. (org.). Relaçōes Intersetoriais do Mercosul e da Economia Brasileira: uma Abordagem de Equilibrio Geral do Tipo Insumo-Produto. Passo Fundo: Univ. de P. Fundo, cap. 6, p. 169-233, 1998.

SYRQUIN, M. GROWTH and structural change in Latin America since 1960: a comparative analysis. Economic Development and Cultural Change, vol. 34, $\mathrm{n}^{\circ} 3,1986$.

SYRQUIN, M. Patterns of Structural Change. In: H. Chenery , H. e Srinivasan, T.N. Handbook of Development Economics: Volume 1. Elsevier Science Publishers B.V.: Amsterdam, 1988.

WAGNER, J.E. e DELLER, S.C. A Measure of Economic Diversity: An Input-Output Approach. Center For Community Economic Development. University of WisconsinExtension/Madison. Staff Paper 93.3, 1993. 


\section{Anexo A}

Mudanças estruturais e padrão setorial da alocação do emprego regional, 1990/2000

\begin{tabular}{|c|c|c|c|}
\hline Regiōes & $\begin{array}{l}\text { Índice de mudança } \\
\text { estrutural(IME) }\end{array}$ & $\begin{array}{l}\text { Índice de diversidade } \\
\text { Setorial(Indice de Gini) }\end{array}$ & $\begin{array}{l}\text { Variação do índice de } \\
\text { diversidade setorial }(\%)\end{array}$ \\
\hline Rondônia & 0,14 & 0,75 & $-5,13$ \\
\hline Acre & 0,10 & 0,79 & $-1,22$ \\
\hline Amazonas & 0,17 & 0,61 & $-4,69$ \\
\hline Roraima & 0,34 & 0,78 & 11,11 \\
\hline Para & 0,11 & 0,66 & 3,08 \\
\hline Amapá & 0,36 & 0,78 & $-9,64$ \\
\hline Tocantins & 0,34 & 0,74 & 13,24 \\
\hline Maranhão & 0,11 & 0,71 & 0,00 \\
\hline Piaui & 0,10 & 0,73 & $-4,00$ \\
\hline Ceara & 0,11 & 0,63 & $-4,62$ \\
\hline Rio Grande do Norte & 0,15 & 0,70 & $-4,23$ \\
\hline Paraiba & 0,12 & 0,69 & $-5,56$ \\
\hline Pernambuco & 0,16 & 0,62 & 3,23 \\
\hline Alagoas & 0,15 & 0,73 & $-4,00$ \\
\hline Sergipe & 0,15 & 0,68 & $-2,86$ \\
\hline Bahia & 0,11 & 0,65 & 3,13 \\
\hline Minas Gerais & 0,12 & 0,53 & 1,89 \\
\hline Espirito Santo & 0,14 & 0,58 & 5,00 \\
\hline Rio de Janeiro & 0,13 & 0,58 & 8,93 \\
\hline São Paulo & 0,15 & 0,44 & 11,90 \\
\hline Paraná & 0,12 & 0,53 & $-1,85$ \\
\hline Santa Catarina & 0,10 & 0,47 & 2,13 \\
\hline Rio Grande do Sul & 0,10 & 0,48 & $-3,92$ \\
\hline Mato Grosso do Sul & 0,17 & 0,68 & 1,49 \\
\hline Mato Grosso & 0,17 & 0,65 & $-1,52$ \\
\hline Goiás & 0,14 & 0,62 & $-6,15$ \\
\hline Distrito Federal & 0,10 & 0,78 & $-1,27$ \\
\hline Brasil & 0,12 & 0,54 & 5,66 \\
\hline Correlação do IME & 1,00 & 0,38 & 0,29 \\
\hline
\end{tabular}

Fonte: elaboração do autor a partir dos dados da RAIS. 